\title{
The Armenian forests: threats to conservation and needs for sustainable management
}

\author{
R. Moreno-Sanchez ${ }^{1}$, H. Sayadyan ${ }^{2}$, R. Streeter ${ }^{3}$ \& J. Rozelle ${ }^{1}$ \\ ${ }^{1}$ Department of Geography and Environmental Sciences, \\ University of Colorado at Denver, USA \\ ${ }^{2}$ Agrarian State University of Armenia, Armenia \\ ${ }^{3}$ Stratus Consulting, Inc., USA
}

\begin{abstract}
In this paper we identify the characteristics of a sustainable forest management strategy and provide specific recommendations to move toward this goal in the forests in Armenia. To provide a context for these recommendations we present brief overviews of Armenian human and physical geography and the forests in the country. Also, we highlight how several crucial issues in the forestry sector have remained unchanged from the Soviet era to the independent period and the implications of this lack of change for the evolution and current state of forests in the country.

Keywords: Armenia, forests, sustainable management, Caucasian region.
\end{abstract}

\section{Introduction}

The forests of the Caucasian region are a hot spot of biodiversity and they contain a large number of endemic plant and animal species [1]. In this drysubtropical region, forests also play a major role in preserving favourable environmental conditions for sustainable development. This is particularly true in small countries like Armenia. The 1988-1994 war with neighboring Azerbaijan and the great social, political and economic changes that have occurred since the country gained independence at the time of the collapse of the United Soviet Socialist Republics (USSR) in 1991 have created tremendous pressures on the Armenian forests [2]. Ongoing developments and policies continue to threaten the quality and extent of Armenian forests $[2,3]$. 
To reverse this trend it is important to revive the Armenian forestry culture and educate a new generation of stakeholders, scientists, resource managers, and policy makers (in Armenia and abroad) about the characteristics, historical evolution, and current extent of the forests in the country. Also, there is a need to analyze and reflect on past and current management and conservation practices, forestry regulations and laws, and the relationship of the Armenian society to the forests. This information and analysis is fundamental in understanding the reasons for change, the current state of the forests ecosystems, and in providing a framework for the development of sustainable management alternatives for the Armenian forests.

In this paper we identify the characteristics of a sustainable forest management strategy and provide specific recommendations to move toward this goal in the forests in Armenia. To provide context for our recommendations, we first present a brief overview of Armenian human and physical geography and the forests of the country. Also, we highlight how several crucial issues in the forestry sector have remained unchanged from the Soviet era to the independent period and the implications of this lack of change for the evolution and current state of the forests in the country.

\section{Overview of Armenian human and physical geography}

Over the centuries, the Republic of Armenia enjoyed brief periods of autonomy and came under the sway of various empires, including the Assyrian, Roman, Byzantine, Arab, Persian and Ottoman. Armenia was incorporated into Russia in 1828 and into the United Soviet Socialist Republics (USSR) in 1920. Independence was achieved after the disintegration of the USSR in 1991. From 1988-1994, Armenia was involved in an armed conflict with Azerbaijan over the Nagorno-Karabakh region. The early years of independence were marked by economic hardships due to disruption in flow of energy and products from former Soviet republics [4].

The constituent 11 provinces have a human population of 3326448 (estimate for 2003 based on the first Armenian census of 2001), which is decreasing at an annual rate of $0.07 \%$, mostly because of emigration. Approximately one third of the total population is concentrated in the capital Yerevan (1 091230 people). Over $98 \%$ of the population aged 15 and over can read and write [4].

The country has a total area of $29800 \mathrm{~km} 2$ (comparable to the size of Belgium). Altitude ranges between $400 \mathrm{~m}$ to $4090 \mathrm{~m}$ above sea level. Armenia is situated in a dry subtropical climatic zone. Precipitation ranges from 250$300 \mathrm{~mm}$ to $1000 \mathrm{~mm}$ per year. Several distinct microclimates are created by the complicated topography. The terrain complexity and microclimatic diversity, as well as the fact that Armenia is located at the crossroads of four different floristic provinces (Old-Mediterranean, Near-east Asian, Iran-Turanian and Caucasian), produce different vegetation types with high biodiversity and high percentages of plant and animal endemism. Today the country is included in the Caucasus and Irano-Anatolian biodiversity hotspots [1]. Biomes range from a semi-desert in 
the Ararat plain to sub-alpine and alpine on the summit of the Aragats Mountain. There are c. 3600 species of high-vascular plants in the country [5-7]. The dendroflora is composed of 110 tree and 152 bush species [5-8].

The country faces several environmental problems and challenges including [4]: (1) soil erosion (It is estimated that two-thirds of the country suffers from heavy to medium erosion processes); [9-12], (2) soil and water pollution from toxic chemicals, (3) irrigation and drinking water shortages, (4) pollution of Lake Sevan (the main source of drinking and irrigation water in Armenia), (5) significant deforestation rates and (6) biodiversity loss.

\section{Characteristics and extent of the forests in Armenia}

We use the terms 'forest cover' or 'forest' to denote high forests (natural or created through plantations) dominated by tree species. The Armenian forests are predominantly composed of complex mixes of broadleaf deciduous tree species (mostly Oak Quercus spp., beech Fagus orientalis, and hornbeam Carpinus betulus and $C$. orientalis) $[2,13]$. Table 1 presents more detailed information on the composition and extent of the forest cover at different points in time.

Table 1: The area (in hectares) and percentage of total forest cover by dominant tree species in 1941 [14], 1956 [15], 1966 [16], 1997 [17] and 1988 [18].

\begin{tabular}{|c|c|c|c|c|c|}
\hline $\begin{array}{l}\text { Dominant tree } \\
\text { species }\end{array}$ & $\begin{array}{l}1941 \\
\text { Area } \\
\text { (ha) }\end{array}$ & $\begin{array}{l}1956 \\
\text { Area } \\
\text { (ha) }\end{array}$ & $\begin{array}{l}1966 \\
\text { Area } \\
\text { (ha) }\end{array}$ & $\begin{array}{l}1977 \\
\text { Area } \\
\text { (ha) }\end{array}$ & $\begin{array}{l}1988 \\
\text { Area } \\
\text { (ha) }\end{array}$ \\
\hline $\begin{array}{l}\text { Mix of oaks } \\
\text { (Quercus spp.) }\end{array}$ & 80241 & 83294 & 87200 & 97852 & 120000 \\
\hline $\begin{array}{l}\text { Beech (Fagus } \\
\text { orientalis) }\end{array}$ & 109201 & 85310 & 89700 & 89533 & 96600 \\
\hline $\begin{array}{l}\text { Hornbeam } \\
\text { (Carpinus spp.) }\end{array}$ & 60365 & 46543 & 46600 & 50976 & 55100 \\
\hline $\begin{array}{l}\text { Pine trees (Pinus } \\
\text { spp.) Mostly from } \\
\text { plantations. }\end{array}$ & 927 & 969 & 2500 & 1295 & 17700 \\
\hline $\begin{array}{l}\text { Juniper (Juniperus } \\
\text { spp.) }\end{array}$ & 7862 & 6357 & 4200 & 12714 & 8400 \\
\hline $\begin{array}{l}\text { Mix of other } \\
\text { broadleaf deciduous } \\
\text { trees (mainly } \\
\text { hornbeam coppice } \\
\text { Carpinus spp., lime } \\
\text { Tilia cordata, ash } \\
\text { Fraxinus spp. and } \\
\text { maple } \text { Acer spp.) }\end{array}$ & 25783 & 10180 & 22800 & 20741 & 36300 \\
\hline Total & 284379 & 241753 & 253000 & 273111 & 334100 \\
\hline
\end{tabular}


Most Armenian forests are found in mountainous terrain between 500 and $2200 \mathrm{~m}$ above sea level. The north-eastern and south-eastern parts of the country and the eastern bank of Lake Sevan have the most favourable climatic and environmental conditions for forests growth. The forest cover is highly fragmented, approximately $62 \%$ being in the north-east, $36 \%$ in the south-east and only $2 \%$ in the central region of the country (see figures 1 and 2).

The numbers in table 1 come from Soviet forest inventories. Unfortunately, these data are the most recent regarding composition and extent of the forest cover. The Soviet estimates of the total area of the forest cover have come into question and have been characterized as unreliable [19]. Hence, Streeter et al [19] recently generated estimations of the extent of the Armenian forest cover using supervised classifications of Landsat satellite images from 1987-1989 (see figure 1) and 2000-2001 (see figure 2). According to their results, in the first period the forest cover was approximately 294,135 ha compared to 246,098 ha in the second period.

The transformations and current state of the Armenian forests result from decades of management policies and forest use practices by several stakeholders and economic activities. Planned industrial production or use of the forests was very limited during the Soviet and independence periods for reasons that we will elaborate on later. Today the Armenian forests can be characterized as overstocked and over-mature forests with low density, low annual growth rates, and poor regeneration.

\section{Forestry in Soviet and independent Armenia}

The most relevant issues that have influenced the current state of the forests in Armenia have changed little from the Soviet era through the independent period [2]. The forests are owned and managed by the Armenian state. Soviet and today's forest laws and regulations state that the forests are to be solely dedicated to protect the environment and other resources and for recreation purposes. Forest management during both periods has been characterized by protectionist policies, limited to sanitation cuts, with no intermediate cuts, and no industrial or commercial utilization of the forest resources. These policies aim to keep the Armenian forests mostly untouched without regard for the needs of the population, and without considering that a certain level of economic use of the forest (for example production of high-value timber from precious species) could be achieved without compromising their extent or capacity to protect other resources. Protectionist policies have had important consequences. First, the forest areas inhabitants and adjacent communities perceive that the forests had little or no monetary value for enhancing their economic situation if they are to be used according to the law. Secondly, there has been no opportunity to develop experience in managing the types of forest existing in Armenia with multiple objectives such as water production, protection of soils, recreation, grazing, and high-value timber production [2]. The later is a fundamental part of a sustainable management strategy. Soviet forest inventories were characterized by the use of 


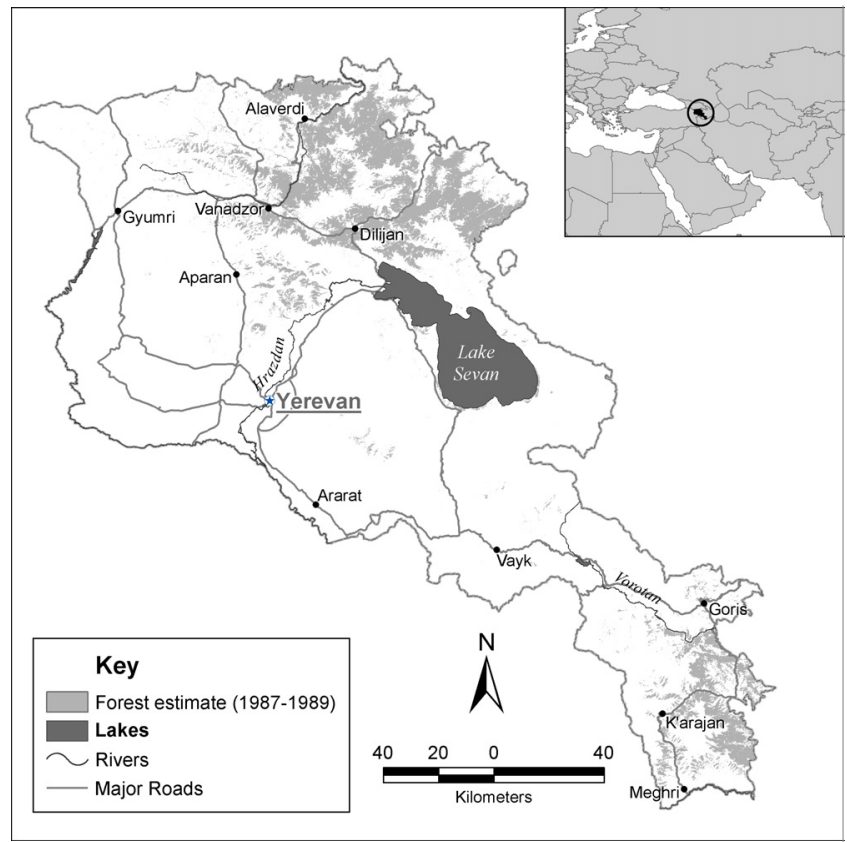

Figure 1: $\quad$ Forest cover estimate from Landsat images for 1987-1989 [19].

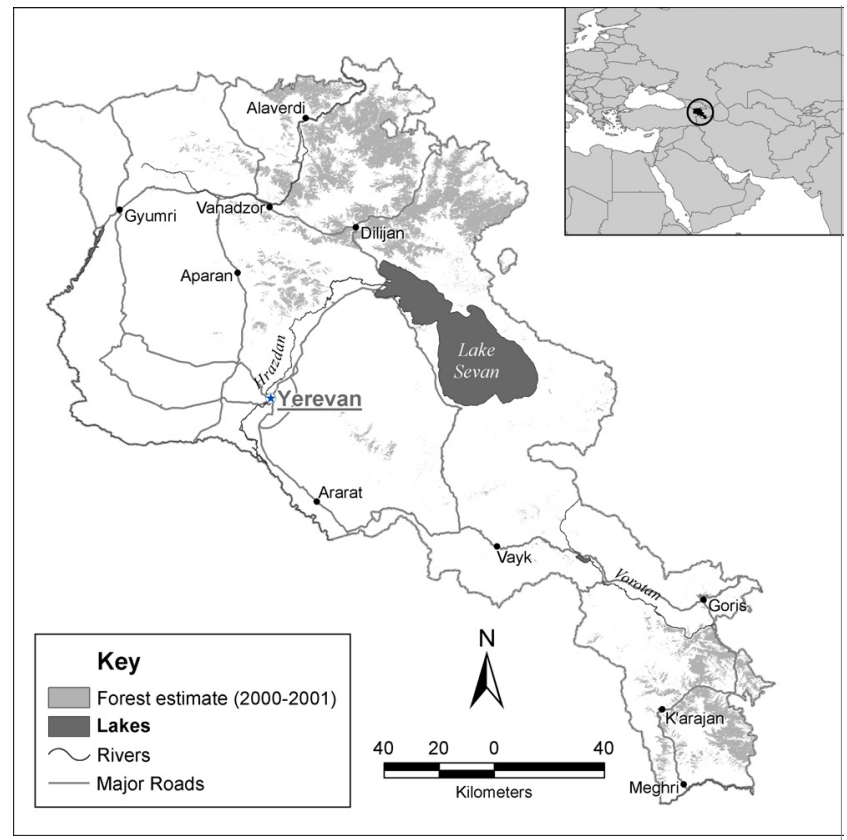

Figure 2: $\quad$ Forest cover estimate from Landsat images for 2000-2001 [19]. 
visual assessments, limited statistical methods, and ground truthing [2]. Since independence, Armenia has not conducted a forest inventory with national coverage $[2,3,19]$.

During the Soviet period, forest education and inventory expertise were concentrated at the regional center in Georgia [2]. This left Armenia without these resources at the time of the collapse of the USSR. In 2003, the first forestry department was established in the State Agrarian University of Armenia. Today Armenia still does not have a dedicated organization to conduct forest inventories, and there is a severe shortage of professionals with forestry education and know-how [2].

The independent period (1991- to date) has been characterized by significant negative impacts on the forests ecosystems. At the time of independence (and until 1994), Armenia was at war with Azerbaijan. Right after independence, all oil, gas, and forest product imports from Russia and other former USSR republics ceased abruptly [2]. These imports used to satisfy most of the energy needs in the country and more than $90 \%$ of the demand for forest products in Armenia. The resulting energy crisis forced many small cities and local forest communities during most of the 1990 s to obtain up to $50 \%$ of their household energy needs from unregulated fuelwood cuttings [2]. The conditions that existed during early independence fostered the creation and growth of a massive blackmarket economy in all sectors, but particularly in the forestry sector. To this day, almost $100 \%$ of forest product production is part of an extensive black-market economy $[2,20]$.

The nature of the illegal cuttings started to change in 1996-1997, when the flow of oil and gas imports returned to almost normal levels. High-grade cuttings for illegal exports to Iran, Turkey and Europe involving the best specimens of high-value timber species replaced cuttings for firewood as the main source of impact to the forests $[2,21]$.

\section{Defining a forest sustainable management strategy}

A sustainable management approach to the Armenian forests has to integrate multiple objectives and use the forests in a manner and rate which will make this resource available to future generations. It will also promote continuous economic benefit, social acceptability, sound environmental conditions for human development and the subsistence of other species. Next, we list what we consider is required to move toward this goal.

(1) It is required to take a holistic view and approach to the management of the forests that include and balance economic, social, and environmental considerations. (2) To be able to achieve point one, it is necessary to have a solid understanding of the functioning, responses, and interactions of the economic, social, and environmental systems involved in the Armenian forests. (3) Sustainable forest management requires: (a) a broader concept of the management unit to include areas beyond the borders of the forest (such as landscape-scale areas defined along ecological boundaries that go beyond 
political and administrative boundaries); (b) solid understanding of the functioning, responses, and interactions of the social, economic, and environmental systems at different temporal and spatial scales; and (c) consideration of a broader array of species within the management units at each temporal and spatial scale. (4) Point number three requires a higher level of cooperation, coordination, collaboration, and sharing of information among stakeholders from diverse sectors, public and private organizations, and countries. (5) Finally, an important activity to promote point four is to educate all the entities as to why and how cooperation, coordination, collaboration, and the sharing of information must take place to move toward sustainable management of resources in general, and forest ecosystems in particular.

None of the above mentioned requirements are easy to achieve and there are numerous cultural, political, economic, scientific, and technological challenges that must be overcome. However, we consider that: (1) There is enough progress on the technological front to start moving toward a better integration and sharing of information; and (2) education, of the society at large and specific stakeholders and organizations, on the need and the issues involved in the points listed in the previous paragraph can have a significant impact on moving toward sustainable management alternatives for the forests in Armenia. Regarding point one, there are significant advances in the creation of standards to enable interoperability between heterogeneous data sources, computer platforms, software, and information systems (see [22] for examples in the area of geographic and health information). To address point two in regard to the forests of Armenia, a website was created to raise awareness of the location and extent of the forests (http://osweb.cudenver.edu/armenia/Index.php). This site also provides wide access to historical data, and to the latest cartographic information regarding the extent of the forests in the country. This website will be translated into Armenian in the near future.

\section{Recommendations for the Armenian forests}

More specifically, in order of priority we suggest that the following actions and activities are required to reduce the threats to the sustainability of the Armenian forest (see [2, 3]) and to start evolving toward sustainable management alternatives. (1) Consider other alternatives for the ownership and organization for management of the forest resources in the country. (2) Review and update forest regulations and laws to make them congruent with the new social, economic, and environmental realities in the country. (3) Increase oversight, accountability, and punishment for corruption and mismanagement in the government (i.e. better governance). (4) Educate (at all levels) the Armenian society and the forest stakeholder in particular regarding the social, economic, and environmental importance and value of the Armenian forest resources; what constitutes a sustainable management strategy for these resources; and what elements and actions are required to move toward this goal. (5) Create a forestry sector infrastructure (professional and technical education centers, support for forestry producers and communities; inventory and monitoring facilities and 
know-how) to support forest management activities. (6) Carry out an efficient and accurate estimation and monitoring of the forest resources in the country. (7) And finally, given that most of the value of the Armenian forest resides in nonmarketable goods and services (e.g. protection of other resources, water production, recreation), study how to quantify and assign monetary compensations for these goods and services that can benefit the national and local economies. There is work being done and progress on several of these issues, but there is still much to be done.

The ownership of the forests by the Armenian state is not conducive to the sustainability of this resource. Lack of economic, human and material resources, administrative red tape, poor implementation of outdated laws and regulations, plus a lack of oversight and corruption are contributing to the mismanagement and degradation of the forests. State ownership of the forests disenfranchises the Armenian society and local forest inhabitants. Economic benefits from any forestry activity must be directly and immediately channeled to local communities. According to the latest forest growth estimates, the Armenian forests can support the commercial production of high-value timber products without compromising their conservation and protection to other resources function [2]. The generation of lawful and regulated economic benefits from the forests in the country would have a large impact on the level of attention given to these resources. As a result, it will have an impact on their conservation and maintain interest in their sustainable management.

Although the evolution and current state of the Armenian forests and forestry sector are the result of a specific set of cultural, political, economic, and environmental conditions, there are many issues that are common to the experiences and development in many parts of the developing world. The sharing of experiences and information is fundamental to avoid repeating mistakes that have been made in the past. It will also avoid going down paths that have proven unsuccessful in the conservation and sustainable management of the world's forest resources.

\section{References}

[1] Conservation International. Biodiversity hotspots. URL http://www. biodiversityhotspots.org/xp/Hotspots/caucasus/biodiversity.xml

[2] Sayadyan, H. \& Moreno-Sanchez, R., Forest policies management and conservation in Soviet (1920-1991) and post-Soviet (1991-2005) Armenia. Environmental Conservation, 33(1), pp 1-13, 2006.

[3] Moreno-Sanchez, R. \& Sayadyan, H., Evolution of the forest cover in Armenia. International Forestry Review, 7(2), pp 113-127, 2005.

[4] CIA (Central Intelligence Agency), The CIA world factbook: Armenia, URL http://www.cia.gov/cia/publications/factbook/geos/am.html

[5] Grigoryan, A.A., Valuable Tree Species and Bushes of Armenia. Yerevan, Armenia: Hayastan Publications, 168 pp. 1979. (In Armenian).

[6] Armenian Ministry of Nature Protection, Hayastani kensabazmazanutyuny (The biodiversity of Armenia). Arajin azgajin 
zekuyc. First National Report-UNDP/GEF/ARM/97/G31/A/1G/99), Yerevan, Armenia, 140 pp. 1999.

[7] Vardanyan, Z.H., Derevya i kustarnikiArmenii v prirode $i$ culture (Trees and Bushes of Armenia in Nature and Culture). Yerevan, Armania: Institut Botaniki NAN Armenii (Institute of Botany of NAS of Armenia), 367 pp. 2003.

[8] Abrahamyan, H.A., Hayastani Antarnery (The Armenian forests). Yerevan, Armenia: Haypethrat Publications, 68 pp. 1960.

[9] Hayrapetyan, E.M., Hoghi erozian ev lernayin hoghagorcutyuny (Soil Erosion and Mountain Horticulture). Yerevan, Armenia: Hayastan Publications, 220 pp. 1976.

[10] Hayrapetyan, E.M., Gyughatntesakan ogtagorcumic durs ekac hogheri iracman ughinery (The Ways of Land Utilization out of Agricultural Cultivation). Yerevan, Armenia: Hayastan Publications, 58 pp. 1979.

[11] Hayrapetyan, E.M., Hoghagitutyun (Soil Science). Yerevan, Armenia: Asoghik, 456 pp. 2000.

[12] Hayrapetyan, E.M., Petrosyan, H.P. \& Zaqoyan, R.H., Haykakan khsh hogheri melioracian, kulturakanacumy evpahpanumy (The Melioration Cultivation and Protection of Soils of Republic of Armenia). Yerevan, Armenia: Hayastan Publications, 499 pp. 1990.

[13] Sayadyan, H.Y., Landscape diversity, planning and optimal forest cover in Armenia. Annals of Agrarian Science, 3(2), pp 38-42, 2005.

[14] Maghakyan, A.K., Rastitelniy pokrov Armyanskoy SSR (Vegetation of Armenian SSR). Moscow-Leningrad, USSR: Akademia nauk SSSR, Otdel Armenii/Botanicheskiy Institute, 76 pp. 1941.

[15] Abrahamyan, H.A. Hayastani Antarnery (The Armenian forests). Yerevan, Armenia: Haypethrat Publications, 68 pp. 1960.

[16] Hakhinyan, H.M., The main tasks of development and intensification of forest farm in Armenia and results of scientific-research works. In: Haykakan gitahetazotakan antarphordzakayani askhatutyunneri joghovacu (Collection of Materials of Armenian Scientific Research Forest Experimental Centre), Volume VII, pp. 18-47. Yerevan, Armenia: Hayastan Publications. 1973.

[17] Makhatadze, L.B., Dubravi Armenii (Oak forests of Armenia). Yerevan, Armenia: Izdatelstvo Akademii Nauk ArmSSR (Publication of Academy of Sciences of Armenian SSR), 327 pp. 1977.

[18] Khurshudyan, P.A., The forest cover of Armenia in historical past, current state and forest ecosystems vulnerability in the case of climate change. In: Armenia-Climate Change Problems, pp. 110-122. Ministry of Nature Protection of Armenia/UNDP Global Ecological Fund (GEF) (in Armenian, resume in English). 1999.

[19] Streeter, R., Moreno-Sanchez, R., Sayadyan, H. \& Wyckoff, J., Deforestation in Armenia: A quantitative estimation using Landsat imagery. Forest Ecology and Management, Forthcoming. 
[20] Armenian Ministry of Nature Protection, Conservation and sustainable use of the forest genetic diversity of Transcaucasus. Forest Research and Experimental Center (FREC), Yerevan, Armenia. 50 pp. 2000.

[21] Sayadyan, H.Y., Illegal logging in Armenia. Draft report, World Bank project, Ensuring sustainability of forests and livelihoods through improved governance and control of illegal logging for economies in transition, World Bank, Yerevan, Armenia, 36 pp. 2005.

[22] Moreno-Sanchez, R., Anderson, G., Cruz, J. \& Hayden, M., The potential for the use of Open Source Software and Open Specifications in creating Web-based cross-border health spatial information systems. International Journal of Geographic Information Science (Forthcoming). 